Título do trabalho

\title{
INFLUÊNCIA DA CONCENTRAÇÃO DE CLORETO E DA CORRENTE NA DEGRADAÇÃO ELETROQUíMICA DO CORANTE VERMELHO DE ALIZARINA S UTILIZANDO ELETRODO ADE ${ }^{\circledR}$
}

Nome do Autor Principal

Eduardo Marques Moreira

Nome da Co-autora

Carla Regina Costa

Nome do Orientador

Artur de Jesus Motheo

Instituição

Universidade de São Paulo - Instituto de Química de São Carlos

Instituição de Fomento

Coordenação de Aperfeiçoamento de Pessoal de Nível Superior - CAPES

E-mail de contato

eduardomarquesmoreira@gmail.com

Palavras-chave

Oxidação anódica. Vermelho de alizarina S. Ânodo dimensionalmente estável.

\section{INTRODUÇÃO}

Os corantes são freqüentemente associados a diversos problemas ambientais. Além de poderem ser tóxicos, esses compostos apresentam a característica particular de dar coloração aos efluentes que os contem o que implica que, além de uma eventual toxicidade, os corantes podem acabar inibindo a fotossíntese devido ao bloqueio da luz solar nos corpos de água (SILVA et al., 2010). 
Dentre os corantes há o VAS, que é uma antraquinona empregada em curtumes para dar cor vermelha aos couros (RHIN, 2008). Os efluentes de curtumes, por sua vez, são caracterizados pelas grandes cargas de compostos orgânicos e também de cloreto (COSTA, 2009). Freqüentemente, os efluentes de curtumes são carregados com muita cor devido ao uso intenso de corantes para tingimento (COSTA, 2009).

No tratamento de efluentes, o uso dos ânodos dimensionalmente estáveis $\left(\mathrm{ADE}^{\circledR}\right)$ tem ganhado espaço, tendo em vista que esses eletrodos são insolúveis e por isso mantém suas dimensões ao longo do uso (ARDIZZONE e TRASATTI, 1996). Esses eletrodos são constituídos por uma mistura de óxidos condutores (eletroativos e eletrocatalisadores) e semicondutores (COSTA, 2009).

Os $A D E^{\circledR}$,s são bastante apropriados para efluentes de curtumes tendo em vista que esses eletrodos são capazes de gerar altas quantidades de cloro ativo em meio de cloreto (COSTA, 2009). Entretanto, nesses eletrodos ocorre grande favorecimento da reação de desprendimento de oxigênio (RDO) (COSTA, 2009). Por tal motivo, óxidos como $\mathrm{SnO}_{2}$ podem ser adicionados ao eletrodo a fim de minimizar os efeitos da RDO (COSTA, 2009).

Trabalhos de CATANHO, MALPASS e MOTHEO, 2006, empregando um eletrodo $A D E^{\circledR}$ de composição nominal $\mathrm{Ti} / \mathrm{Ru}_{0,3} \mathrm{Ti}_{0,7} \mathrm{O}_{2}$ obtiveram bons resultados de remoção de cor nos processos de degradação eletroquímica e fotoeletroquímica.

Freqüentemente, análises de ultravioleta/visível (UV/Vis), demanda química de oxigênio (DQO) e carbono orgânico total (COT) são usadas para monitorar quedas de cor, quantidade de matéria oxidável e quantidade de matéria orgânica, respectivamente.

\section{OBJETIVO GERAL}

Avaliar a eficiência de degradação do Corante Vermelho de Alizarina S sob diversas condições a partir de dados cinéticos de UV/Vis, DQO e COT.

\section{OBJETIVOS ESPECÍFICOS}

O objetivo desse trabalho é avaliar a degradação do corante Vermelho de Alizarina $S$ usando-se um eletrodo do tipo $A D E^{\circledR}$ de composição Ti/lr ${ }_{0,01} S_{0,99}(\mathrm{Sb}) \mathrm{O}_{2}$ em 
presença de cloreto (concentrações de 0,02 e 0,05 mol. $\mathrm{L}^{-1}$ ) em meio ácido controlado por tampão inerte de fosfato $\left(\mathrm{H}_{3} \mathrm{PO}_{4} / \mathrm{NaH}_{2} \mathrm{PO}_{4} 0,2\right.$ mol.L $\left.{ }^{-1}\right)$. Para avaliar a degradação do corante foram usadas as técnicas de UV/Vis, COT e DQO.

\section{METODOLOGIA}

No presente experimento foi usada uma célula fotoeletroquímica do tipo filtroprensa contendo uma malha de $\mathrm{ADE}^{\circledR}$ como eletrodo de trabalho (composição $\left.\mathrm{Ti} / / \mathrm{r}_{0,01} \mathrm{Sn}_{0,99}(\mathrm{Sb}) \mathrm{O}_{2}\right)$ e uma placa de aço inoxidável como contra-eletrodo. Usou-se um fluxo de $290 \mathrm{~mL} \cdot \mathrm{min}^{-1} \mathrm{e}$ variou-se a corrente entre os valores de 0,2 e 0,5 A.

As concentrações de cloreto testadas foram de 0,02 e 0,05 mol. $\mathrm{L}^{-1}$. A concentração de corante usada foi de $700 \mathrm{mg} \cdot \mathrm{L}^{-1} \mathrm{em}$ tampão fosfato $0,2 \mathrm{~mol} . \mathrm{L}^{-1} \mathrm{de}$ tampão $\mathrm{H}_{3} \mathrm{PO}_{4} / \mathrm{NaH}_{2} \mathrm{PO}_{4}(\mathrm{pH} \sim 1,9)$.

As eletrólises tiveram duração de $5 \mathrm{~h}$ e foram monitoradas através das quedas de cor, carbono orgânico total (método NPOC) e demanda química de oxigênio. Tratou-se um volume de $300 \mathrm{~mL}$ de solução sendo que nas duas primeiras horas foram coletadas amostras em intervalos de tempo de 15 em 15 minutos. Após esse tempo, foram coletadas amostras de uma em uma hora. A temperatura foi mantida constante em $35 \pm$ $1^{\circ} \mathrm{C}$.

\section{RESULTADOS}

Observou-se que a eficiência de degradação aumenta com a corrente aplicada e com a concentração de cloreto, até certos limites. Foram feitos também cálculos de eficiência de corrente percentual a fim de se obter mais um parâmetro de comparação.

Quando usada a concentração de cloreto de $0,02 \mathrm{~mol}^{-\mathrm{L}^{-1}}$ e corrente de 0,2 A, observaram-se remoções de COT de $13,5 \%$, DQO de $28,4 \%$ e cor $94,1 \%$, obtendo-se uma eficiência de corrente de 9,7\%. Já com concentração de cloreto de $0,02 \mathrm{~mol}^{-\mathrm{L}^{-1}} \mathrm{e}$ corrente aplicada de 0,5 A, as remoções de COT, DQO e cor foram de 19,5\%,33,0\% e $96,4 \%$, respectivamente sendo a eficiência de corrente igual a $5,8 \%$. 
Usando-se a concentração de cloreto de 0,05 mol. $\mathrm{L}^{-1}$ e corrente de 0,2 A, observaram-se remoções de COT de 16,5\%, DQO de 31,9\%, e cor de 94,5\%, obtendo-se nessa condição uma eficiência de corrente igual a 12,1\%. Para a concentração de cloreto de $0,05 \mathrm{~mol} . \mathrm{L}^{-1}$ e corrente de 0,5 A, observou-se que as quedas de COT, DQO e cor foram de $16,8 \%, 41,3 \%$ e $96,1 \%$, respectivamente, tendo-se assim uma eficiência de corrente de $4,8 \%$.

Pelos resultados mostrados, vê-se que a concentração de cloreto influencia suavemente na eficiência de degradação. Nota-se que para a corrente de 0,2 A, um aumento da concentração de cloreto de 0,02 para 0,05 mol. $\mathrm{L}^{-1}$ provoca um aumento da remoção de COT de 13,5 para 16,5\%. Entretanto, para a corrente de 0,5 A, interessantemente 0 aumento da concentração de cloreto de 0,02 para 0,05 mol.L ${ }^{-1}$ diminui a remoção de COT de 19,5 para $16,8 \%$.

Isso pode indicar que em valores mais altos de concentração de cloreto há muita evasão de gás cloro do sistema, o que faz com que o mesmo não seja utilizado na degradação das substâncias orgânicas ou talvez ocorra a formação de espécies recalcitrantes organocloradas no meio. Outro fator que chama a atenção é que a queda de DQO na corrente de 0,5 A e concentração de cloreto de 0,05 mol. $\mathrm{L}^{-1}$ é de 41,3\%, o que indica que, pela discrepância com o valor de queda de COT, deve ter havido a formação de compostos organoclorados difíceis de serem degradados mesmo pela solução digestora de DQO. Análises de organohalogenados adsorvidos (AOX) estão sendo realizadas para averiguar essa hipótese.

As quedas de absorbância mostram que para a remoção de cor o tratamento foi bastante eficiente nas quatro eletrólises. Através das quedas de absorbância vê-se que as reações de degradação têm cinética de pseudo-primeira ordem e que em aproximadamente duas horas de eletrólise a constante de velocidade da reação muda, chegando a diminuir quase dez vezes. Isso mostra que conforme a concentração do corante cai, a reação de desprendimento de oxigênio passa a ser bastante favorecida, prejudicando assim a eficiência de degradação.

Pelos valores de eficiência de corrente, nota-se que a condição em que se obteve os melhores resultados é aquela onde a concentração de cloreto foi de $0,05 \mathrm{~mol}^{-1} \mathrm{~L}^{-1}$ e a corrente aplicada foi de 0,2 A. 


\section{CONSIDERAÇÕES FINAIS}

A partir dos dados obtidos nota-se que, pelos valores de eficiência de corrente, a melhor condição a ser utilizada é aquela cuja concentração de cloreto é de $0,05 \mathrm{~mol}^{-1} \mathrm{e}$ a corrente aplicada é a de 0,2 A. Pelos mesmos valores de eficiência de corrente, nota-se também a eletrólise efetuada a 0,2 A e concentração de cloreto de 0,02 mol. $\mathrm{L}^{-1}$ foi bastante eficiente. A discrepância entre os valores de queda de DQO e TOC deve-se provavelmente a formação de espécies resistentes à oxidação por solução digestora, 0 que pode mascarar os resultados de análise de DQO.

\section{REFERÊNCIAS}

ARDIZZONE, S.; TRASATTI, S. Interfacial properties of oxides with technological impact in electrochemistry. Advances in Colloid and Interface Science, v. 64, p. 173$251,1996$.

CATANHO, M.; MALPASS, G. R. P.; MOTHEO, A. J. Avaliação dos tratamentos eletroquímico e fotoeletroquímico ma degradação de corantes têxteis. Química nova, v. 29, p. 983-989, 2006.

COSTA, C. R. Tratamento de efluentes provenientes de curtumes utilizando os processos eletroquímico e fotoeletroquímico. Tese (Doutorado em Química) Faculdade de Filosofia, Ciências e Letras de Ribeirão Preto, Universidade de São Paulo, Ribeirão Preto, 2009.

RHIN, L. Generalidades sobre La obtención de las principales clases de cueros y el empleo de los colorantes de hulla en la tintura de los cueros. Badische Anilin \& SodaFabrik, Buenos Aires, 2008.

SILVA, A. D. S. ; ROCHA, O. R. S.; PAIVA, A. F.; RADNAI, E. P. S.; TRUCHLAEFF, C.; DA MOTTA, M.; SILVA, V. L. Remoção do corante têxtil remazol Black por dióxido de cloro. Disponível em: <http://www.abq.org.br/cbq/2007/trabalhos/5/5-127-294.htm>. Acesso em: 18.08.2010. 